\title{
Sleep Deprivation by Exposure to Novel Objects Increases Synapse Density and Axon-Spine Interface in the Hippocampal CA1 Region of Adolescent Mice
}

\author{
(1)Giovanna Maria Spano, Sebastian Weyn Banningh, William Marshall, ㄴoisa de Vivo, Michele Bellesi,

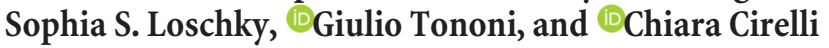 \\ Department of Psychiatry, University of Wisconsin-Madison, Madison, Wisconsin 53719
}

\begin{abstract}
Sleep has been hypothesized to rebalance overall synaptic strength after ongoing learning during waking leads to net synaptic potentiation. If so, because synaptic strength and size are correlated, synapses on average should be larger after wake and smaller after sleep. This prediction was recently confirmed in mouse cerebral cortex using serial block-face electron microscopy (SBEM). However, whether these findings extend to other brain regions is unknown. Moreover, sleep deprivation by gentle handling was reported to produce hippocampal spine loss, raising the question of whether synapse size and number are differentially affected by sleep and waking. Here we applied SBEM to measure axon-spine interface (ASI), the contact area between pre-synapse and post-synapse, and synapse density in CA1 stratum radiatum. Adolescent YFP-H mice were studied after $6-8 \mathrm{~h}$ of sleep $(S=6)$, spontaneous wake at night $(\mathrm{W}=4)$ or wake enforced during the day by novelty exposure ( $\mathrm{EW}=4$; males/females balanced). In each animal $\geq 425$ ASIs were measured and synaptic vesicles were counted in $\sim 100$ synapses/mouse. Reconstructed dendrites included many small, nonperforated synapses and fewer large, perforated synapses. Relative to S, ASI sizes in perforated synapses shifted toward higher values after W and more so after EW. ASI sizes in nonperforated synapses grew after EW relative to $S$ and $W$, and so did their density. ASI size correlated with presynaptic vesicle number but the proportion of readily available vesicles decreased after EW, suggesting presynaptic fatigue. Thus, CA1 synapses undergo changes consistent with sleep-dependent synaptic renormalization and their number increases after extended wake.
\end{abstract}

Key words: CA1; electron microscopy; hippocampus; mouse; sleep; synapse

Significance Statement

Sleep benefits learning, memory consolidation, and the integration of new with old memories, but the underlying mechanisms remain highly debated. One hypothesis suggests that sleep's cognitive benefits stem from its ability to renormalize total synaptic strength, after ongoing learning during wake leads to net synaptic potentiation. Supporting evidence for this hypothesis mainly comes from the cerebral cortex, including the observation that cortical synapses are larger after wake and smaller after sleep. Using serial electron microscopy, we find here that sleep/wake synaptic changes consistent with sleep-dependent synaptic renormalization also occur in the CA1 region. Thus, the role of sleep in maintaining synaptic homeostasis may extend to the hippocampus, a key area for learning and synaptic plasticity.

\section{Introduction}

It has been proposed that sleep serves to renormalize the total amount of synaptic strength after it increases during wake be-

Received Feb. 15, 2019; revised May 24, 2019; accepted June 10, 2019.

Author contributions: G.T. and C.C. designed research; G.M.S., S.W.B., L.d.V., M.B., and C.C. performed research; G.M.S., S.W.B., W.M., L.d.V., M.B., S.S.L., and C.C. analyzed data; W.M., G.T., and C.C. wrote the paper.

This work was supported by NIH Grants DP 100579 (G.T.), 1R01MH091326 (G.T.), 1R01MH099231 (G.T., C.C.), 1P01NS083514 (G.T., C.C.)

The authors declare no competing financial interests.

Correspondence should be addressed to Chiara Cirelli at ccirelli@wisc.edu.

W. Marshall's present address: Department of Mathematics and Statistics, Brock University, St. Catharines, ON, L2S 3A1, Canada. cause of ongoing learning, which is mainly mediated by synaptic potentiation (Tononi and Cirelli, 2014). According to this hypothesis, synaptic renormalization is required because stronger synapses need more energy and supplies and are prone to saturation. Synaptic renormalization should occur mainly during sleep because, when the brain is disconnected from the environment,

L. de Vivo's present address: School of Physiology, Pharmacology and Neuroscience, University of Bristol, Bristol BS8 1TD, UK.

M. Bellesi's present address: School of Physiology, Pharmacology and Neuroscience, University of Bristol, Bristol BS8 1TD, UK.

https://doi.org/10.1523/JNEUROSCI.0380-19.2019

Copyright $\odot 2019$ the authors 
neural circuits can be reactivated off-line in a comprehensive manner, promoting the integration of new and old memories and restoring the brain's ability to learn (Tononi and Cirelli, 2014).

The great majority of synapses in the mammalian brain are glutamatergic, excitatory synapses whose postsynaptic component consists of a protrusion emerging from the dendritic shaft, called a spine (Holtmaat and Svoboda, 2009; Harris and Weinberg, 2012; Berry and Nedivi, 2017). Experiments testing the role of sleep in synaptic renormalization have so far mainly used molecular and electrophysiological markers of excitatory synaptic strength (Tononi and Cirelli, 2014; Cirelli, 2017). For instance, it was found that mean expression levels of synaptic AMPA receptors are higher after wake than after sleep in rat cortex and hippocampus and in mouse whole forebrain (Vyazovskiy et al., 2008; Diering et al., 2017). Moreover, excitatory postsynaptic potentials are larger after wake than after sleep in cerebral cortex (Vyazovskiy et al., 2008) and in hippocampal CA1 and CA3 regions (Lubenov and Siapas, 2008; Norimoto et al., 2018). Stronger synapses are also larger (Holtmaat and Svoboda, 2009; Nishiyama and Yasuda, 2015). Thus, if sleep rebalances synaptic strength, synapses should be smaller after sleep than after wake. This prediction was recently confirmed using serial block-face electron microscopy (SBEM) in layer 2 of primary motor and primary sensory cortex of 1-month-old adolescent mice. Specifically, we reconstructed $\sim 7000$ synapses and measured the axon-spine interface (ASI), the direct area of contact between pre-synapse and post-synapse. ASI size correlates with the area of the postsynaptic density (PSD) and they both grow after synaptic potentiation (Desmond and Levy, 1988; Buchs and Muller, 1996; Fukazawa et al., 2003; Cheetham et al., 2014). We found that ASI size was on average $18 \%$ lower after $6-8$ h of sleep compared with $6-8 \mathrm{~h}$ of wake, independent of whether wake occurred during the day or the night (de Vivo et al., 2017).

Whether broad structural synaptic changes because of sleep and wake can be observed outside the cortex remains unclear. Moreover, using Golgi and Dil staining methods a recent study found that mice forced to stay awake for $5 \mathrm{~h}$ by gentle handling showed broad decreases in spine density and dendritic length in the CA1 region of the hippocampus (Havekes et al., 2016) and more limited changes in the dentate gyrus (Raven et al., 2019). These changes, which disappeared after $3 \mathrm{~h}$ of recovery sleep, were interpreted as inconsistent with sleep-dependent synaptic renormalization (Havekes et al., 2016). However, synapse size was not measured in these experiments, leaving open the possibility that sleep loss affects number and size of hippocampal synapses in opposite directions.

Here we applied SBEM to the CA1 area of three groups of mice selected according to the same behavioral criteria used to study cortical synapses (de Vivo et al., 2017): mice sleeping during the day (S), mice spontaneously awake at night (W), and mice subjected to enforced waking during the day (EW) via exposure to novel objects. We focused on the CA3 to CA1 synapses in the middle of the stratum radiatum, where sleep deprivation was reported to cause the largest spine loss (Havekes et al., 2016). At both ultrastructural and functional levels, these synapses are among the best studied in the entire brain, with an established role in plasticity, learning, and memory (Debanne et al., 1996; Toni et al., 2001; Ganeshina et al., 2004; Nicoll and Schmitz, 2005; Nicholson et al., 2006; Harris and Weinberg, 2012).

\section{Materials and Methods}

Animals. We used 1-month-old homozygous B6.Cg-Tg(Thy1-YFP)16)rs/J transgenic mice (IMSR catalog\# JAX:003709, 78; RRID:IMSR_JAX:003709) that express yellow fluorescent protein (YFP) in a subset of cortical pyramidal neurons (Feng et al., 2000). This strain was used to perform SBEM studies in the cerebral cortex (de Vivo et al., 2017; Bellesi et al., $2018 \mathrm{a}, \mathrm{b})$ and developmental changes in the sleep/wake pattern in the course of adolescence had previously been well characterized in these mice (Nelson et al., 2013). All animal procedures followed the National Institutes of Health Guide for the Care and Use of Laboratory Animals and facilities were reviewed and approved by the IACUC of the University of Wisconsin-Madison and were inspected and accredited by the Association for Assessment and Accreditation of Laboratory Animal Care.

Experimental groups. Three groups of mice were used, selected according to the same criteria used in the previous ultrastructural analysis of cortical synapses (de Vivo et al., 2017). Eight of the 14 mice used in the present study were also used by de Vivo et al. (2017). Sleeping mice (S, $n=6)$ were killed during the light phase (3:30-5:30 P.M.) at the end of a long period of sleep ( $>45 \mathrm{~min}$, interrupted by periods of wake of $<4$ $\min$ ), and after spending at least $75 \%$ of the previous $6-8 \mathrm{~h}$ asleep. Mice subjected to enforced waking (EW: $n=4$ ) were kept awake for the first $6-8 \mathrm{~h}$ of the day using novel objects and by tapping on the cage whenever the animals appeared drowsy. This method was validated in previous studies using EEG-implanted mice (Bellesi et al., 2013, 2015) and leads to a reduction of total sleep $>95 \%$ during the sleep deprivation procedure. EW mice were never disturbed when spontaneously awake, grooming, feeding, or drinking, and were killed at the same circadian time as the $\mathrm{S}$ group (2:00-4:45 P.M.). Spontaneously awake mice (W: $n=4)$ were killed during the dark phase ( 2:00-3:30 A.M.) at the end of a long period of wake ( $>1 \mathrm{~h}$, interrupted by periods of sleep of $<5 \mathrm{~min}$ ), and after spending at least $70 \%$ of the previous $6-7 \mathrm{~h}$ awake. In each group the number of male and female mice was balanced. All animals were maintained in environmentally controlled recording chambers with ad libitum access to food and water (12 h light/dark cycle; lights on at 8:00 A.M.). At the beginning of each dark period a running wheel and one to two novel objects were introduced in each recording chamber, to ensure enriched housing conditions and facilitate the light/dark entrainment of the rest/activity cycle. Running wheels and novel objects were removed during the light period, except in the case of EW mice. Sleep/waking behavior was determined by continuous monitoring with infrared cameras (OptiView Technologies), to avoid possible tissue damage and inflammation because of the implant of electrodes for polysomnographic recording. In previous experiments we showed that video-monitoring consistently estimates total sleep time with $\geq 90 \%$ accuracy, although it cannot distinguish NREM sleep from REM sleep (Maret et al., 2011). Motor activity was quantified by custom-made video-based motion detection algorithms (MATLAB), as detailed by Bellesi et al. (2013).

Electron microscopy experiments. Mice were anesthetized with isoflurane ( $3 \%$ volume to oxygen), then transcardially perfused for $30 \mathrm{~s}$ with normal saline $\left(0.9 \%, 41^{\circ} \mathrm{C}\right)$ followed by $10 \mathrm{~min}$ of $2.5 \%$ glutaraldehyde and $4 \%$ paraformaldehyde dissolved in $0.1 \mathrm{~m}$ sodium cacodylate buffer, $\mathrm{pH} 7.4,41^{\circ} \mathrm{C}$. Brains were removed and kept in the same fixative overnight at $4^{\circ} \mathrm{C}$. Tissue slices $(120 \mu \mathrm{m})$ were cut on a vibratome and kept in a cryoprotectant solution until the day of processing. Small blocks of tissue $\left(1 \mathrm{~mm}^{2}\right.$ ) from the CA1 region (from bregma, AP: $-1.8 \mathrm{~mm}$, lateral: $1.2 \mathrm{~mm}$ ) were excised under a stereomicroscope and stained as detailed by Wilke et al. (2013) and de Vivo et al. (2017). Staining was performed blind to experimental condition. Briefly, the tissue was rinsed in cacodylate buffer, incubated in the dark for $1 \mathrm{~h}$ on ice with a solution of $1 \%$ potassium ferrocyanide $/ 2 \%$ osmium tetroxide, and exposed to a solution of $1 \%$ thiocarbohydrazide for $20 \mathrm{~min}$ at room temperature. Afterward, the sample was placed in $2 \%$ osmium tetroxide for $30 \mathrm{~min}$ and incubated with $1 \%$ uranyl acetate $(2 \mathrm{~h}$ at room temperature followed by overnight at $4^{\circ} \mathrm{C}$ ). The following day, the tissue was stained with a solution of lead aspartate for $30 \mathrm{~min}$ at $60^{\circ} \mathrm{C}, \mathrm{pH} 5.5$, and dehydrated using ice-cold solutions of freshly prepared $35,50,75,80,90,95$, and $100 \%$ ethanol. The sample was then placed in propylene oxide twice for $10 \mathrm{~min}$ and impregnated with 25, 50, and 75\% Durcupan ACM resin (Electron Microscopy Science) mixed with propylene oxide ( $2 \mathrm{~h}$ each). The tissue was then placed in fresh $100 \%$ Durcupan several times, flat embedded with ACLAR embedding film (Electron Microscopy Science) and kept in a $60^{\circ} \mathrm{C}$ oven for $48-72 \mathrm{~h}$. After polymerization, the stained tissue was 
Table 1. Summary of ultrastructural measures in the CA1 region

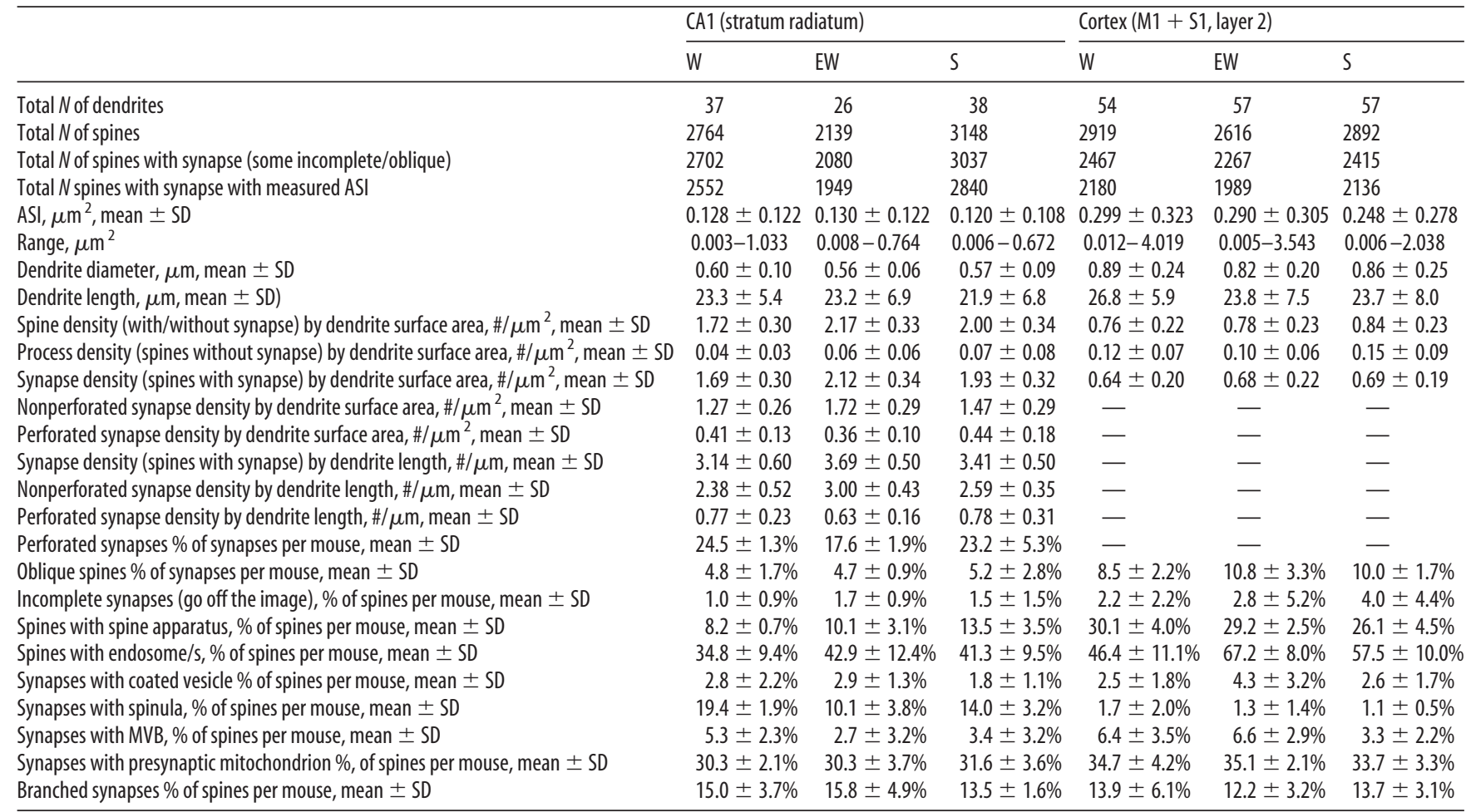

Cortical measures previously reported by de Vivo et al. (2017) are also shown to facilitate the comparison between the two regions. All protrusions are defined as spines. In oblique spines the ASI could not be measured because the synapse was oriented obliquely or orthogonally to the cutting plane. SD for the cortex used a pooled estimate based on two sampled regions.

excised under a stereomicroscope and attached on the tip of a metal pin using conductive epoxy resin (Chemtronics), which minimizes specimen charging during imaging.

Imaging. Samples were imaged in a $\sum$ IGMA VP field emission scanning electron microscope with the following parameters: aperture 30 $\mu \mathrm{m}$; high vacuum, acceleration voltage $1.7 \mathrm{kV}$, image size of $5000 \times 5000$ pixels, image resolution ( $x-y$ plane) of $4 \mathrm{~nm}$. One or two stacks of $\sim 500$ images each were acquired per mouse $(\sim 20 \times 20 \times 25 \mu \mathrm{m})$ in the middle of the stratum radiatum of the CA1 region. Images were Gaussian filtered and automatically aligned using the open source software Fiji (Schindelin et al., 2012). Ultrathin sections were cut at a nominal thickness of $50 \mathrm{~nm}$. Average actual section thickness for each stack was estimated using the cylindrical diameters method (Fiala and Harris, 2001) and did not differ across the 3 experimental groups [mean $\pm \mathrm{SD}$ (in $\mathrm{nm}) ; \mathrm{S}=52.63 \pm 2.97$; $\mathrm{W}=52.73 \pm 3.30 ; \mathrm{EW}=53.15 \pm 1.93$; Kruskal-Wallis $p=0.90]$. Dendritic segments and all their protrusions were segmented manually in TrakEM2 (Cardona et al., 2012) by six trained annotators who were blind to experimental condition. We randomly selected spiny dendritic segments whose length was at least $8 \mu \mathrm{m}$ [mean $\pm \mathrm{SD}$ (in $\mu \mathrm{m}) ; \mathrm{S}=$ $23.34 \pm 5.45 ; \mathrm{W}=23.22 \pm 6.87 ; \mathrm{EW}=21.89 \pm 6.84 ;$ linear mixed effects (LME) model $p=0.6191]$ and whose diameter ranged between 0.41 and $0.92 \mu \mathrm{m}$. Distribution of dendritic diameters was balanced across experimental groups [mean $\pm \mathrm{SD}($ in $\mu \mathrm{m}) ; \mathrm{S}=0.57 \pm 0.09 ; \mathrm{W}=0.60 \pm 0.10$; $\mathrm{EW}=0.56 \pm 0.06$; LME model $p=0.5545]$. We targeted the middle of the stratum radiatum, $150-200 \mu \mathrm{m}$ from the CA1 pyramidal cell body layer, the same area targeted in several previous studies (Harris and Stevens, 1989; Bourne and Harris, 2011). Of note, the distance between the cell body layer and the border of the hippocampal fissure is the same in rats and mice (Routh et al., 2009), hence our region of interest may closely overlap with the area studied in rats (Bourne and Harris, 2011). To restrict the analysis to pyramidal cells we avoided all dendritic segments with few or no spines.

All protrusions were defined as "spines" (as suggested by Holtmaat and Svoboda, 2009) and divided in spines with synapses and spines lacking synapses. In each mouse the protrusions without synapses, also called processes, were very rare $(N$ per dendrite surface area; mean $\pm S D ; S=$ $0.073 \pm 0.079 ; \mathrm{W}=0.036 \pm 0.035 ; \mathrm{EW}=0.056 \pm 0.056 ; \mathrm{LME}$ model $p=$
0.369; (Table 1), consistent with results from the CA1 region of adult rats (Bourne and Harris, 2011). A synapse was defined by the presence of a presynaptic bouton with at least two synaptic vesicles within a $50 \mathrm{~nm}$ distance from the cellular membrane facing the spine, a visible synaptic cleft, and PSD. In total, 101 dendritic branches were segmented $(S=38$; $\mathrm{W}=37$; EW $=26$ ). All segmentation data were tested for accuracy and consistency by the same experienced tracer (C.C.).

The ASI was traced at the interface between the spine head and the presynaptic terminal or bouton, and computed as described by Bellesi et al. (2015). Specifically, the region of contact between the two apposed objects was outlined (on the spine head side) in each individual section using the arealist brush suitably set at 1 pixel size. In this way, a quasitwo-dimensional sheet-like object representing the interfaced region was created along the $z$ dimension. The total surface area was calculated by computing the smoothed upper bound surface, according to the following formula:

\section{Smoothed upper bound surface}

$$
=\sum_{k=0}^{n}\left(P_{s}(a) \times \frac{1}{2} T\right)+\left(P_{s}(b) \times \frac{1}{2} T\right)+[A(a)-A(b)],
$$

where $n$ is the number of sections, $a$ and $b$ are the traced elements at the top and bottom of a section $k$ of thickness $T, P$ s is the smoothed perimeter, and $A$ is the area (Cardona et al., 2012). Finally, the area of the traced element in the section $k=1$ and in the section $k=n$ were subtracted from the smoothed upper bound surface value and the result was divided by 2 to get an approximate value of the apposed surface (AS). The ASI was not segmented in a subset of "oblique" spines whose synapses were oriented obliquely or orthogonally to the cutting plane ( $\sim 5 \%$ in each stack, across all groups; Table 1). The presence of the following structures was recorded for each spine: spine apparatus, spinula/s in the head or neck of the spine, mitochondria in the presynaptic element, and components of the non-smooth endoplasmic reticulum (non-SER) classified according to (Cooney et al., 2002), including tubules, small uncoated vesicles, large coated or uncoated vesicles, and multivesicular bodies (MVBs). Mitochondria were always present along the dendrites but almost never found 
in the spines, in line with previous reports (Knott et al., 2006; Kasthuri et al., 2015). Synapses were classified as nonperforated or perforated based on presence/absence of a continuous PSD, spinula/s, and/or spine apparatus. To identify perforated synapses, the presence of spinula/s and/or spine apparatus was a useful additional criterion because the clear presence of a discontinuity in the PSD could be missed depending on the spine orientation.

In a subset of dendrites we reconstructed in 3D the apposing axonal bouton and counted the synaptic vesicles. On average, boutons were segmented in 2-3 dendrites in each mouse, for a total of $\sim 100$ boutons per animal. For each dendrite all boutons contacting single spines were segmented. Multisynaptic boutons, which make synapses with multiple spines, were excluded because their vesicles could not always be unequivocally assigned to a single spine. Multisynaptic boutons accounted for $\sim$ one-half of all boutons in all mice, with no difference across groups (percentage of all boutons; mean $\pm \mathrm{SD}, \mathrm{S}=52.9 \pm 6.6 ; \mathrm{W}=49.6 \pm 6.1$; EW 51.9 \pm 3.6). Synaptic vesicles were manually annotated using the ball tool available in TrackEM2. Only structures that had a round shape with a clear membrane were marked as vesicles. When visible in the same location in more than one section, vesicles were counted only the first time they appeared. Structures faintly or very darkly stained, or with an incomplete membrane, or with a diameter of $<30 \mathrm{~nm}$, were not counted. The total number of vesicles and the number of "near vesicles", defined as those within $130 \mathrm{~nm}$ from the ASI, were counted. The distance of each vesicle from the ASI was computed by using a custom-made script in TrakEM2, which calculated the shortest path between a ball object and the nearest vertex point of ASI defined as a set of unique vertices of a meshed surface.

Experimental design and statistical analysis. Statistical analysis was performed using LME models that include both random and fixed effects (Laird and Ware, 1982). The use of LME models was preferred over traditional ANOVA methods for several reasons. One reason is the ability to handle unbalanced data (e.g., differing numbers of dendrites sampled from each mouse, differing numbers of synapses measured from each dendrite). Another benefit of LME models, highly relevant for the current study, is the ability to measure covariates at different levels within the model; for example, perforation is measured at the level of individual synapses, while spine density is measured at the level of dendrites.

The general matrix form of the LME is as follows:

$$
y=Z u+X \beta+\epsilon,
$$

where,

$$
u \sim N(0, \Sigma)
$$

and

$$
\epsilon \sim N\left(0, I \sigma^{2}\right) .
$$

In this model, $y$ is the vector of response variables, $u$ is a vector of random effects (independent and normally distributed with mean zero and covariance $\sum$ ), and $\beta$ is the vector of fixed effects. Design matrices $Z$ and $X$ link the response variables to the random and fixed effects, and $\varepsilon$ is the residual error, assumed to be independent and normally distributed with constant variance $\sigma^{2}$.

To select the model structure, we started with a model that includes random intercepts (for each mouse and dendrite as appropriate). We then used the Akaike information criterion (AIC) to identify the optimal set of fixed effects (the ones that minimize the AIC). If the fixed effect structure contained any interaction terms involving within-subject factors, we then expanded the random effects structure to include a random slope for these parameters in addition to the random intercept, as this is necessary to accurately test for the significance of such interactions (Barr, 2013). Parameter estimation of LMEs was performed using numerical maximum likelihood estimators, implemented in $\mathrm{R}$ by the lmer() function of the lme4 package (Bates et al., 2015). To test the significance of effects in the LME model, we used likelihood ratio tests. Post hoc tests were performed using the glht() function of the multcomp package in $\mathrm{R}$, with $p$ values adjusted for multiple comparisons using the single-step

\begin{tabular}{|c|c|c|c|}
\hline & & Estimate & SE \\
\hline \multicolumn{4}{|c|}{ LME model: total synapse density, \#/surface area } \\
\hline Random effects & SE & & \\
\hline Mouse (intercept) & 0.2084 & & \\
\hline Residual & 0.2418 & & \\
\hline Fixed effects & Level & & \\
\hline Intercept & & 2.1289 & 0.1147 \\
\hline \multirow[t]{3}{*}{ Condition } & EW (reference) & 0 & 0 \\
\hline & SW & -0.4251 & 0.1600 \\
\hline & $S$ & -0.1909 & 0.1482 \\
\hline \multicolumn{4}{|c|}{ LME model: nonperforated synapse density, \#/surface area } \\
\hline Random effects & SE & & \\
\hline Mouse (Intercept) & 0.1656 & & \\
\hline Residual & 0.2011 & & \\
\hline Fixed effects & Level & & \\
\hline Intercept & & 1.6453 & 0.0919 \\
\hline \multirow[t]{3}{*}{ Condition } & EW (reference) & 0 & 0 \\
\hline & SW & -0.4306 & 0.1299 \\
\hline & $S$ & -0.2533 & 0.1188 \\
\hline \multicolumn{4}{|c|}{ LME model: perforated synapse density, \#/surface area } \\
\hline Random effects & SE & & \\
\hline Mouse (intercept) & 0.0837 & & \\
\hline Residual & 0.1142 & & \\
\hline Fixed effects & Level & & \\
\hline Intercept & & 0.3978 & 0.0476 \\
\hline \multirow[t]{3}{*}{ Condition } & EW (reference) & 0 & 0 \\
\hline & SW & 0.0276 & 0.0672 \\
\hline & $S$ & 0.0747 & 0.0615 \\
\hline
\end{tabular}

Table 2. Parameter estimates for the LME models used to assess changes in synapse density

Residual plots showed no evidence against the assumptions of constant variance and normality, with the exception of the model for nonperforated synapse density, where mild violations of the normality assumption were present in the upper tail.

method (Bretz et al., 2011). The details of all LME models are included in Tables 2-4.

Clustering analysis. For every synapse, we determined whether its nearest neighbor, defined as the synapse on the same dendrite with the closest $Z$ value, was perforated or nonperforated. In the absence of clustering, perforated and nonperforated synapses would be equally likely to have a perforated nearest neighbor. By using a generalized LME model, we found instead that there was a strong trend for an interaction between synapse type and nearest neighbor type ( $p=0.0593$; see Results).

\section{Results}

Three groups of mice were used (Fig. 1A), selected according to the same strict sleep/waking criteria applied for the ultrastructural analysis of cortical synapses (de Vivo et al., 2017). In fact, 8 of the 14 mice used in the current study were also used by de Vivo et al. (2017). S and EW mice were collected in the middle of the day. $S$ mice spent the last $6-8 \mathrm{~h}$ mostly asleep $(n=6$, percentage of time asleep in the last $6 \mathrm{~h}$, mean $\pm \mathrm{SD}=83.8 \pm 6.6$; percentage of sleep in the last hour $=88.8 \pm 7.9$ ), whereas EW mice were kept continuously awake by exposure to novel objects ( $n=4$; Fig. $1 B)$. W mice were collected in the middle of the night after having been spontaneously awake for most of the last 6-7 h $(n=4$, percentage of time awake in the last $6 \mathrm{~h}$, mean $\pm \mathrm{SD}=85.9 \pm 7.8$; percentage of wake in the last hour $=85.0 \pm 4.1$; Fig. $1 B$ ). In each mouse SBEM was used to acquire stacks of $\sim 500$ images $\left(\sim 10,000 \mu \mathrm{m}^{3}\right)$ in the middle of the stratum radiatum of the CA1 region (150-200 $\mu \mathrm{m}$ from the CA1 pyramidal cell body layer; Fig. $1 C)$. Stacks were automatically aligned and spiny dendritic segments were randomly selected within each block, balanced in length and diameter size across groups (see Materials and Methods; Fig. 1C). In each dendritic segment, all protrusions (also called spines; see Materials and Methods) were manually seg- 
Table 3. Parameter estimates for the LME models used to assess changes in ASI

\begin{tabular}{|c|c|c|c|}
\hline & & Estimate & SE \\
\hline \multicolumn{4}{|c|}{ LME model: $\log (A S I)$, all synapses; non-constant variance } \\
\hline Random effects & SE & & \\
\hline Dendrite (intercept) & 0.0482 & & \\
\hline Mouse (intercept) & 0.0999 & & \\
\hline Residual & 0.6315 & & \\
\hline Fixed effects & Level & & \\
\hline Intercept & & -2.5182 & 0.1010 \\
\hline Synapse density & Continuous (Linear) & -0.0658 & 0.0404 \\
\hline \multirow[t]{3}{*}{ Condition } & EW (reference) & 0 & 0 \\
\hline & SW & -0.1763 & 0.0763 \\
\hline & $S$ & -0.1874 & 0.0687 \\
\hline \multirow{2}{*}{ Perforated } & NP (reference) & 0 & 0 \\
\hline & $P$ & 1.3641 & 0.0154 \\
\hline \multicolumn{4}{|c|}{ LME model: $\log (A S I)$, nonperforated synapses } \\
\hline Random effects & SE & & \\
\hline Dendrite (intercept) & 0.0705 & & \\
\hline Mouse (intercept) & 0.1072 & & \\
\hline Residual & 0.6962 & & \\
\hline Fixed effects & Level & & \\
\hline Intercept & & -2.4221 & 0.1245 \\
\hline Synapse density & Continuous (Linear) & -0.1127 & 0.0759 \\
\hline \multirow[t]{3}{*}{ Condition } & EW (reference) & 0 & 0 \\
\hline & SW & -0.1989 & 0.0845 \\
\hline & $S$ & -0.1822 & 0.0759 \\
\hline \multicolumn{4}{|c|}{ LME model: sqrt(ASI), perforated synapses } \\
\hline Random effects & SE & & \\
\hline Dendrite (intercept) & 0.0194 & & \\
\hline Mouse (intercept) & 0.0263 & & \\
\hline Residual & 0.1143 & & \\
\hline Fixed effects & Level & & \\
\hline Intercept & & 0.5394 & 0.0150 \\
\hline \multirow[t]{3}{*}{ Condition } & EW (reference) & 0 & 0 \\
\hline & SW & -0.0331 & 0.0208 \\
\hline & $S$ & -0.0518 & 0.0193 \\
\hline
\end{tabular}

A log transformation (all, nonperforated) or a square root transformation (perforated) was applied to the ASI values to ensure the residuals had an approximate Gaussian distribution. Analyzing the residuals of an initial model (all synapses) revealed that the perforated and nonperforated synapses have different levels of variance. To account for this, a variance-weighted model was fit to equalize the variance across the two categories (parameters reported in the table). From Q-Q plots of the residuals we found no evidence against the normality assumptions.

mented by trained annotators blind to experimental condition. Overall, across all mice 101 dendritic branches were segmented $(\mathrm{S}=38 ; \mathrm{W}=37 ; \mathrm{EW}=26)$ for a total of 8051 protrusions (Fig. 2). Of these spines, 7819 had a synapse, and in 7341 of them the ASI could be fully traced and measured ( $N$ of ASIs, $\mathrm{S}=2840 ; \mathrm{W}=2552 ; \mathrm{EW}=1949$; at least 425 ASIs/mouse; Fig. $1 D$; Table 1).

\section{The distribution of ASI sizes in CA1 synapses is bimodal,} because of a sizable proportion of large, perforated synapses In the middle of the stratum radiatum, the dendritic spines of CA1 pyramidal neurons represent the postsynaptic component of axospinous synapses established by Schaffer collaterals from ipsilateral CA3 pyramidal neurons, by collaterals from contralateral CA3 pyramidal neurons, and by associational fibers from CA3 cells in other lamellae (Sorra and Harris, 1993). In all mice the ASI size of these synapses varied greatly even along the same dendritic branch, spanning from 0.0032 to $1.0331 \mu \mathrm{m}^{2}$. The majority of ASIs were of small and medium size, as is the case in layer 2 of primary motor and sensory cortex (de Vivo et al., 2017). However, the distribution of hippocampal ASI sizes was bimodal rather than log-normal as in cortex, because of the presence of a relatively large number of medium and large ASIs. Thus, overall ASI sizes were smaller in the CA1 region than in cortex, in line
Table 4. Parameter estimates for the LME models used to assess changes in vesicles

\begin{tabular}{|c|c|c|c|}
\hline & & Estimate & SE \\
\hline \multicolumn{4}{|l|}{ LME model: $\log ($ total +1$)$} \\
\hline Random effects & SE & & \\
\hline Dendrite (Intercept) & 0.0839 & & \\
\hline Mouse (Intercept) & 0.2772 & & \\
\hline Residual & 0.5500 & & \\
\hline Fixed effects & Level & & \\
\hline Intercept & & 5.1680 & 0.1807 \\
\hline \multirow[t]{3}{*}{ Condition } & EW (reference) & 0 & 0 \\
\hline & SW & -0.7498 & 0.2397 \\
\hline & $S$ & -0.2606 & 0.2227 \\
\hline ASI & Continuous (linear) & 0.5574 & 0.0313 \\
\hline \multirow[t]{3}{*}{ Condition $\times$ ASI } & EW (reference) & 0 & 0 \\
\hline & SW & -0.0990 & 0.0418 \\
\hline & $S$ & -0.0616 & 0.0392 \\
\hline \multicolumn{4}{|l|}{ LME model: $\log ($ near +1$)$} \\
\hline Random effects & SE & & \\
\hline Dendrite (Intercept) & 0.0460 & & \\
\hline Mouse (Intercept) & 0.2474 & & \\
\hline Residual & 0.5029 & & \\
\hline Fixed effects & Level & & \\
\hline Intercept & & 4.7404 & 0.1610 \\
\hline \multirow[t]{3}{*}{ Condition } & EW (reference) & 0 & 0 \\
\hline & SW & -0.7737 & 0.2135 \\
\hline & $S$ & -0.1821 & 0.1984 \\
\hline ASI & Continuous (linear) & 0.8070 & 0.0286 \\
\hline \multirow[t]{3}{*}{ Condition $\times$ ASI } & EW (reference) & 0 & 0 \\
\hline & SW & -0.1545 & 0.0382 \\
\hline & $S$ & -0.0954 & 0.0357 \\
\hline \multicolumn{4}{|l|}{ LME model: sqrt(near/total) } \\
\hline Random effects & SE & & \\
\hline Mouse (Intercept) & 0.0554 & & \\
\hline Mouse (ASI) & 0.0152 & & \\
\hline Residual & 0.1440 & & \\
\hline Fixed effects & Level & & \\
\hline Intercept & & 0.7766 & 0.0223 \\
\hline \multirow[t]{3}{*}{ Condition } & EW (reference) & 0 & 0 \\
\hline & SW & 0.0363 & 0.0183 \\
\hline & $S$ & 0.0509 & 0.0170 \\
\hline ASI & Continuous (log) & 0.0742 & 0.0183 \\
\hline
\end{tabular}

A log transformation was applied to the number of total and near vesicles to give the residuals an approximate Gaussian distribution. Because some synapses had zero vesicles, we added one to the total/near value before applying the transformation to ensure the log was well defined. For both total and near vesicles, a Q-Q plot showed mild violations of the normality assumption in the lower tail due to boundary effects (boundary at 0 ). A square-root transformation was applied to the ratio of near to total vesicles to give the residuals an approximate Gaussian distribution. The $Q-Q$ plot showed mild violations of the normality assumption because of boundary effects at both ends of the range (boundaries at 0 and 1 ).

with published evidence (Bourne and Harris, 2011), but medium and large spines accounted for a greater proportion of the entire CA1 population (Fig. $3 A$ ).

The bimodal distribution of ASI size was present across all mice and in the majority of dendrites in each mouse (Fig. 3B), consistent with the presence of two distinct populations of hippocampal axospinous synapses, nonperforated and perforated synapses, as described in the literature. The distinctive feature that defines the two groups is a continuous (nonperforated) or discontinuous (perforated) PSD, but several other differences distinguish the two synapse types morphologically and functionally. Nonperforated synapses reside in thin spines that almost always lack spinulas (small projections from spines) or a spine apparatus. They are numerous but usually small and weak: they contain few AMPA receptors and up to $40 \%$ of them are silent, i.e., they only express NMDA receptors. Perforated synapses instead are less frequent but larger, usually harbored at large mushroom-shaped spines that often contain spinulas and/or a 


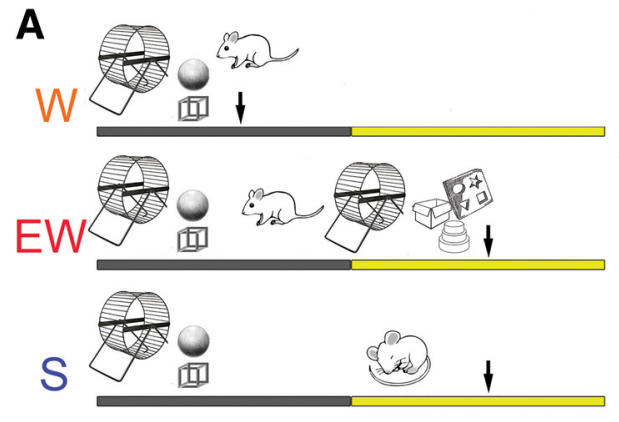

B

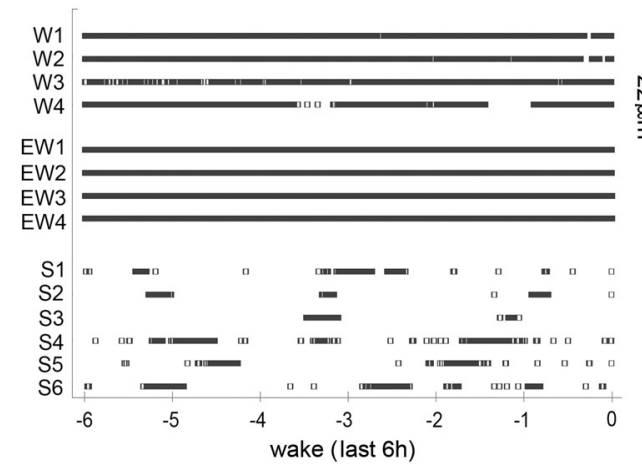

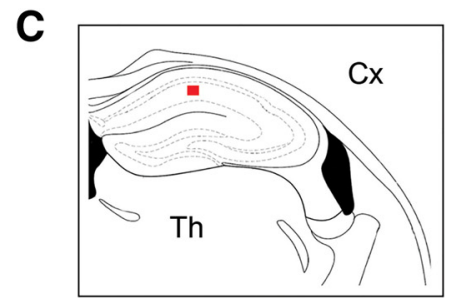

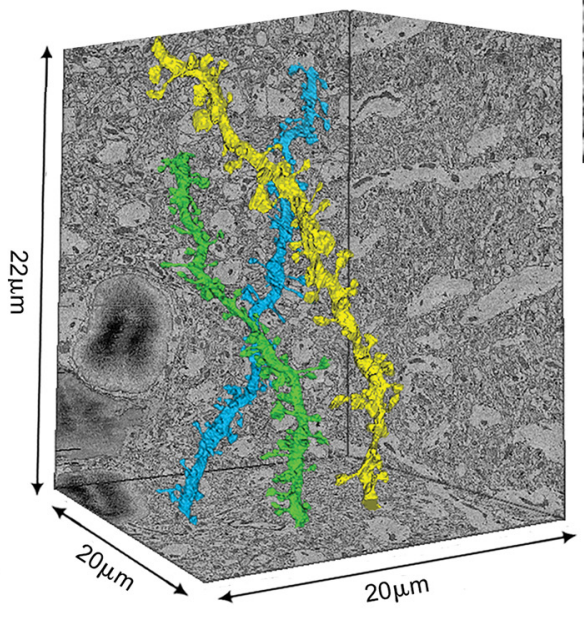

Figure 1. A, Experimental design: W mice were spontaneously awake in the first part of the night; EW mice were kept awake during the day by exposure to novel objects, whereas $S$ mice were allowed to sleep. Like W mice, EW and S mice had access to running wheel and novel objects the night before brain collection, which is indicated by an arrow. $\boldsymbol{B}$, Time spent awake in each mouse (4-6/group) during the last $6 \mathrm{~h}$ before brain collection. $C$, Top, Schematic representation of a coronal section of the mouse brain: the area of SBEM data collection in the middle of the CA1 stratum radiatum is indicated by a red box. Cx, Cortex; Th, thalamus. Bottom, Example of 3D reconstruction of three dendritic branches. $D$, Raw image of a CA1 spine containing a synapse and its 3D reconstruction (spine and dendrite in light green, ASI in red; axonal bouton in light blue, synaptic vesicles in black). Scale bars: 2D, 300 nm; 3D, $1 \mu \mathrm{m}$.

spine apparatus, and are strong, with a large number of AMPA and NMDA receptors (Nusser et al., 1998; Sorra et al., 1998; Takumi et al., 1999; Ganeshina et al., 2004; Nicholson et al., 2006; Nicholson and Geinisman, 2009).

Although expected, the bimodal distribution of ASI sizes makes the statistical analysis more challenging because results are difficult to interpret unless a bimodal distribution is split in two unimodal distributions. Using a threshold to divide "large ASI" synapses and "small ASI" synapses was not an option, because the two populations overlapped significantly in terms of ASI size, making any criteria based on size arbitrary (Fig. 3B). Thus, we used the established ultrastructural criteria mentioned above to classify each synapse as nonperforated or perforated, the latter when it contained a discontinuous PSD, spinula/s and/or a spine apparatus (Fig. 3C). This splitting procedure was successful: when combined, the two populations identified using these criteria could account for the bimodal distribution (Fig. 3D). Note that the two populations overlapped significantly in ASI size (Fig. $3 D$ ), again confirming that this parameter alone could not be used to reliably define the two synapse types.

Consistent with previous studies (Menon et al., 2013) we found that perforated synapses included the largest synapses and represented $\sim 22 \%$ of all synapses across the three experimental groups ( $N$ synapses/dendrite surface area, $\# / \mu \mathrm{m}^{2}$, mean $\pm \mathrm{SD}$ : total $1.89 \pm 0.36$; nonperforated $1.46 \pm 0.32$; perforated $0.41 \pm$ $0.14)$. The distribution of ASI sizes followed a log-normal distribution in nonperforated synapses but not in the perforated ones (Fig. 3D). Of note, across all groups there was a strong trend for an interaction between synapse type and nearest neighbor type (see Materials and Methods, Clustering analysis; LME model $p=$ $0.0593)$. Specifically, the perforated synapses were more likely to have a perforated nearest neighbor than the nonperforated synapses, suggesting a clustering of synapses by type.

\section{Extended wake increases the density of nonperforated synapses}

We first asked whether sleep and wake can affect synapse number and if so, whether the effects differ with synapse type. Consistent with previous evidence (Bourne and Harris, 2011), total synapse density in the CA1 region was higher than in cortex ( $N$ of synapses per dendrite surface area, $\# / \mu \mathrm{m}^{2}$, mean $\pm \mathrm{SD}$; $\mathrm{S}$ groups: cortex $=0.69 \pm 0.19 ;$ CA $1=1.93 \pm 0.32$; Table 1 ). Almost all CA1 spines contained a synapse, also in line with results from the CA1 region of adult rats (Bourne and Harris, 2011), and the density of the protrusions without synapses did not differ across groups ( $N$ per dendrite surface area; mean $\pm \mathrm{SD} ; \mathrm{S}=0.073 \pm$ $0.079 ; \mathrm{W}=0.036 \pm 0.035 ; \mathrm{EW}=0.056 \pm 0.056 ; \mathrm{LME}$ model, $p=$ $0.369)$.

We tested for sleep/wake effects on synapse density, separately for nonperforated and perforated synapses, by applying LME models with condition as a fixed effect and mouse intercept as a random effect (Methods, Table 2). When compared across groups, the total number of nonperforated synapses showed a significant effect of condition $(p=0.0158)$ and post hoc tests found increased density of nonperforated synapses in EW relative to $\mathrm{W}(p=0.0025)$ and a trend for an increase in EW relative to $\mathrm{S}$ $(p=0.0832)$. Conversely, there was no effect of condition on the density of perforated synapses $(p=0.4728$; Fig. $4 A$ ). Similar results were obtained when synapse density was expressed per dendrite length (data not shown).

Using a generalized LME model we also tested for changes in the proportion of nonperforated and perforated synapses and 


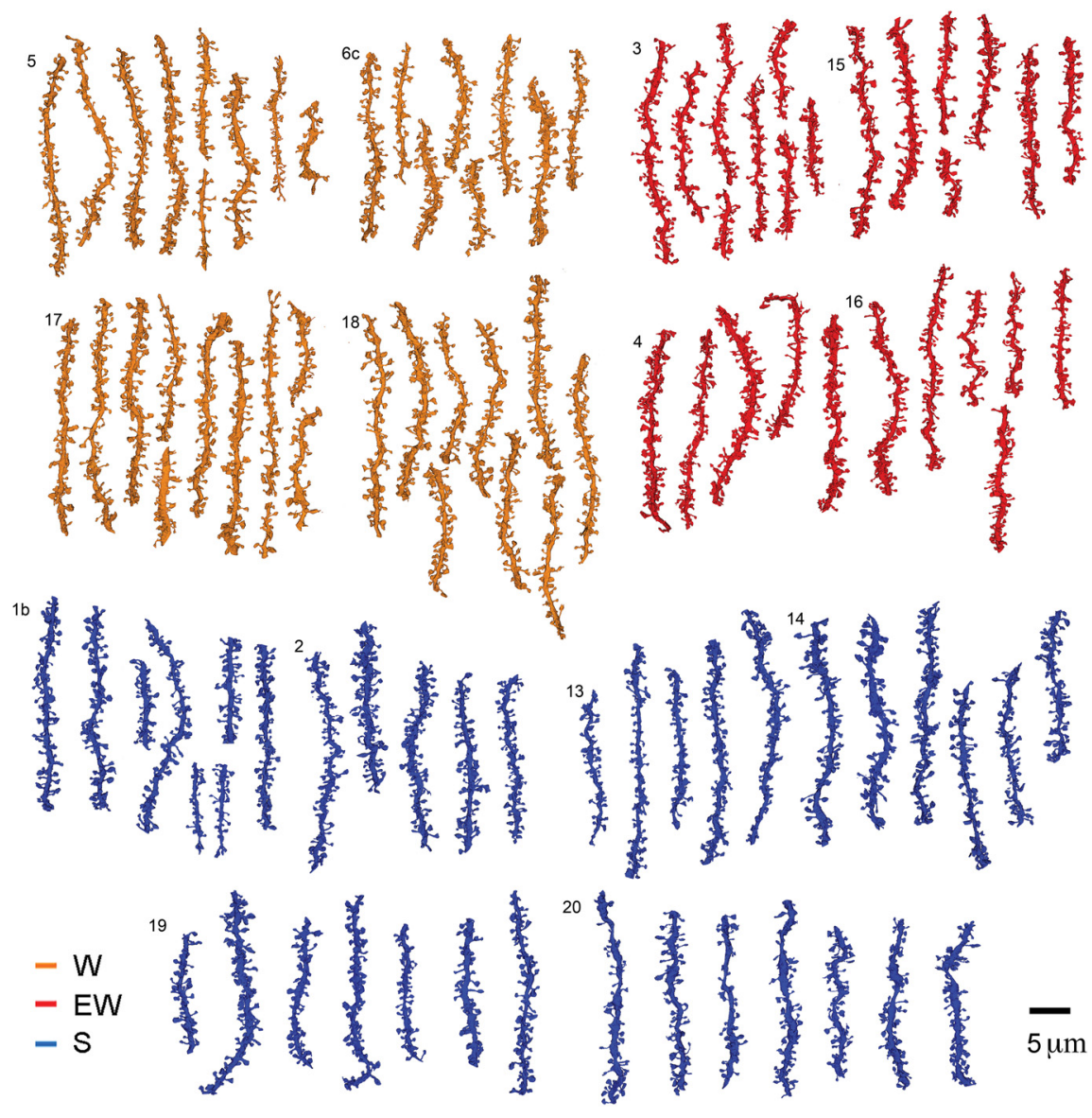

Figure 2. Reconstruction of all dendritic segments used in the study. W: 4 mice, 37 dendrites; EW: 4 mice, 26 dendrites; S: 6 mice, 38 dendrites. Each mouse is identified by a number.

found a significant effect of condition $(p=0.0141)$, with $\mathrm{S}$ $(23.2 \%)$ and $\mathrm{W}(24.5 \%)$ both having greater proportion of perforated synapses than EW (17.6\%). The proportion of branched synapses (sharing the same neck) did not change across groups $(p=0.2005)$.

In summary, EW leads to an increase in synaptic density relative to both $\mathrm{S}$ and $\mathrm{W}$, and the effect is specific for nonperforated synapses, which account for the majority of CA1 synapses and are generally smaller than perforated synapses. Note that in both the apical and the basal dendrites of CA1 pyramidal neurons synapse density decreases with increasing distance from the soma, because of a specific decrease in the number of nonperforated synapses (Menon et al., 2013). These regional changes, however, cannot account for our results, because we focused on the apical dendrites located in the middle of the stratum radiatum and the distribution of dendritic diameters was balanced across experimental groups (see Materials and Methods).

\section{The distribution of ASI sizes shifts toward higher values with extended wake}

We then asked whether ASI sizes change with sleep and wake by comparing their distribution separately for nonperforated and perforated synapses. For nonperforated synapses, we found that the distribution of ASIs was shifted toward significantly larger sizes in EW relative to $S$ (KS test; $D=0.093, p=2.3 \mathrm{e}-7$ ) and in EW relative to $\mathrm{W}(D=0.085, p=8.6 \mathrm{e}-6)$, but not in $\mathrm{W}$ relative to $S(D=0.018, p=0.917)$. We also found significant evidence against a scaling relationship between EW and $\mathrm{S}$ (KS test; $D=$
0.051, $p=0.019)$ as well as between EW and $\mathrm{W}(D=0.040, p=0.118$; Fig. $4 B)$. In other words, the differences in ASI size for nonperforated synapses could not be explained by a scaling relationship. Because the density of nonperforated synapses increases with EW, we also tested whether this effect could have contributed to the described differences in ASI size. We fitted a LME model with condition and synapse density as fixed effects, and mouse and dendrite as random effects (see Materials and Methods; Table 3). Consistent with the results obtained with the KS test we found a strong trend for a main effect of condition ( $p=0.0594)$ and post hoc tests identified a significant increase in ASI size in EW relative to $S$ (19.9\% increase, $p=$ $0.0430)$ and EW relative to $W(22 \%$ increase, $p=0.0484)$, with no difference between $\mathrm{S}$ and $\mathrm{W}(p=0.9731)$. Thus, changes in ASI size in nonperforated synapses are independent of changes in spine density. Note that the LME model focuses on differences in the mean ASI value, whereas the KS test considers the entire distribution of ASI sizes, which may explain why the LME found a strong trend but the effect was not as significant as with the KS test.

For perforated synapses, we found significant differences in the distribution of ASI sizes among all 3 conditions: EW greater than $\mathrm{S}$ (KS test; $D=0.206, p=$ $3.8 \mathrm{e}-9)$, EW greater than $\mathrm{W}(D=0.132$, $p=0.001)$ and $\mathrm{W}$ greater than $\mathrm{S}(D=0.083, p=0.018)$. In this case the differences could be explained by scaling, i.e., in all cases we found no evidence against a scaling relationship (EW and S, $D=0.072, p=0.174 ; \mathrm{W}$ and $\mathrm{EW}, D=0.062, p=0.345 ; \mathrm{W}$ and $\mathrm{S}, D=0.054, p=0.284$; Fig. $4 C$ ).

In summary, relative to sleep the distribution of ASI sizes in perforated synapses shifts toward significantly higher values already after a few hours of spontaneous wake, and even more so after extended wake, and these changes occur without changes in spine density. The distribution of ASI sizes in the larger group of nonperforated synapses, instead, does not differ between sleep and spontaneous wake but shifts toward significantly higher values after extended wake relative to both groups. In this type of synapse, spine density also increases after extended wake relative to both sleep and spontaneous wake.

The findings reported so far were obtained using separate LME models for nonperforated and perforated synapses. When all synapses were considered together in a single LME model (using synapse type as fixed categorical variable; Tables 2, 3) results were very similar to those obtained for nonperforated synapses. Specifically for synapse density, there was a strong trend effect of condition ( $p=0.0578)$, with post hoc tests finding that $\mathrm{W}$ had significantly lower synapse density than EW ( $p=0.0217)$, whereas synapse density in $\mathrm{S}$ did not significantly differ from either W ( $p=0.2424$ ) or EW ( $p=0.4016$; Fig. $4 A$, right). For ASI size, there were significant differences between EW and S (KS test; $D=0.056, p=0.001)$, EW and W $(D=0.047, p=0.015)$, but not $\mathrm{W}$ and $\mathrm{S}(D=0.03, p=0.156)$ and the differences in ASI could 
A

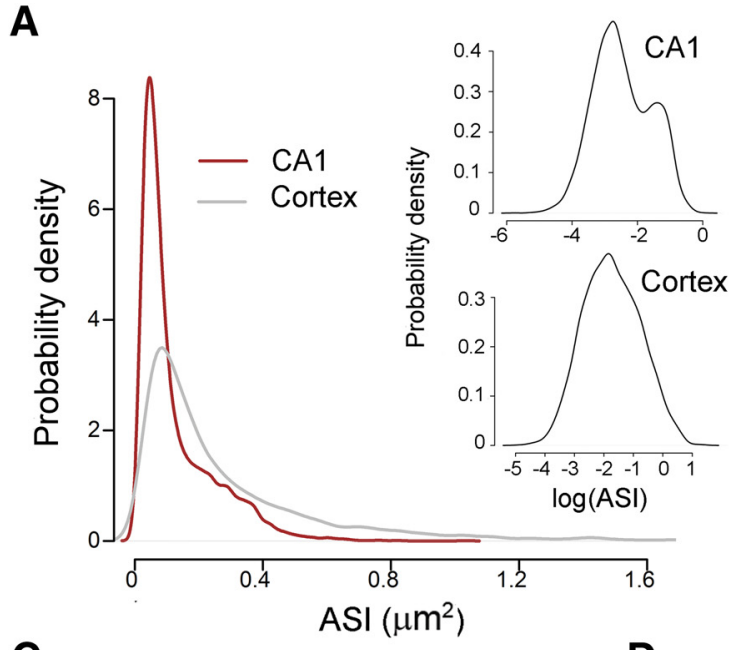

C

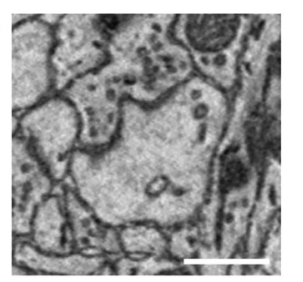

D
B
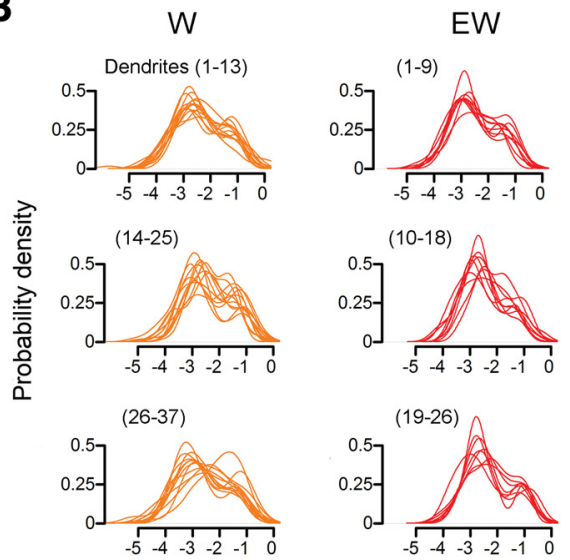

$\log (\mathrm{ASI})$
EW

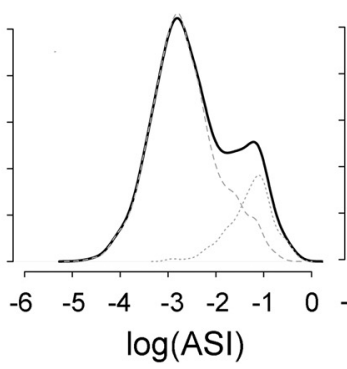

$\mathrm{S}$
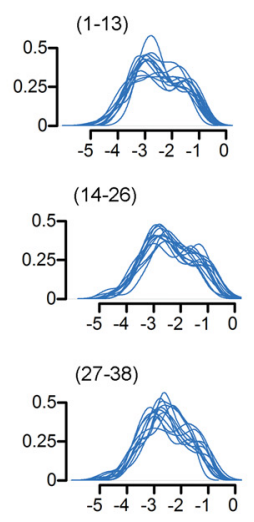

W

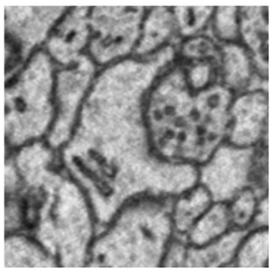

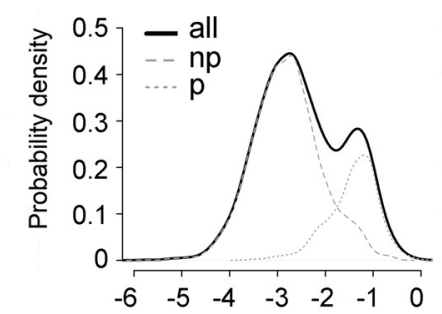

Figure 3. A, Distribution of ASI sizes in the CA1 region and cerebral cortex, across all three experimental groups. Insets, same on a log scale. $B$, Distribution of ASI sizes in the CA1 region, shown on a log scale separately for each dendrite. C, Examples of perforated synapses with a discontinuous PSD (left) and a spine apparatus (right). Scale bar, $300 \mathrm{~nm}$. D, Distribution of ASI sizes for each experimental group shown on a log scale for all synapses, and separately for nonperforated ( $\mathrm{np}$ ) and perforated ( $\mathrm{p}$ ) synapses.

not be explained by a scaling relationship (EW vs $S, D=0.046, p=0.015 ; \mathrm{EW}$ vs W, $D=0.044, p=0.030)$.

The number of readily available synaptic vesicles decreases after extended wake

In the CA1 area, as in other brain regions, a positive correlation has been observed between presynaptic structural measures of synaptic strength, such as size of the active zone and number of synaptic vesicles, and postsynaptic structural markers, including spine head volume and size of the PSD (Harris and Stevens, 1989; Schikorski and Stevens, 1997; Bartol et al., 2015). In a subset of dendrites we reconstructed the apposing axonal bouton and counted the synaptic vesicles $(\sim 100$ boutons/mouse). Only boutons contacting single spines were considered (see Materials and Methods), because the vesicles of multisynaptic boutons sometimes were difficult to assign to a specific spine (Fig. $5 A$ ). The total number of vesicles and the number of near vesicles, defined as those within $130 \mathrm{~nm}$ from the ASI, were
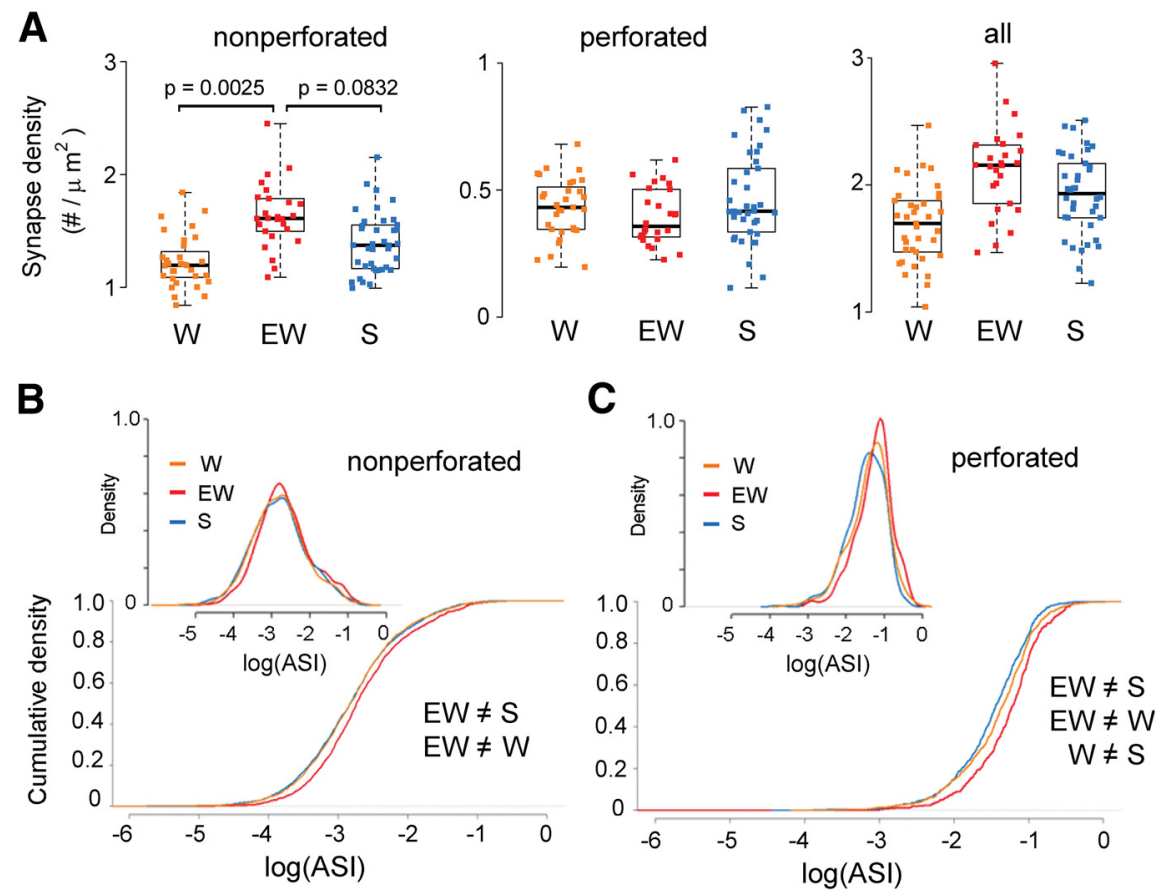

Figure 4. A, Synapse density ( $N$ of synapses per dendrite surface area) in each experimental group, shown for nonperforated, perforated, and all synapses. Each dot is one dendrite. B, C, Distribution and cumulative plots of ASI sizes in each group, on a log scale, shown for nonperforated and perforated synapses. 
A
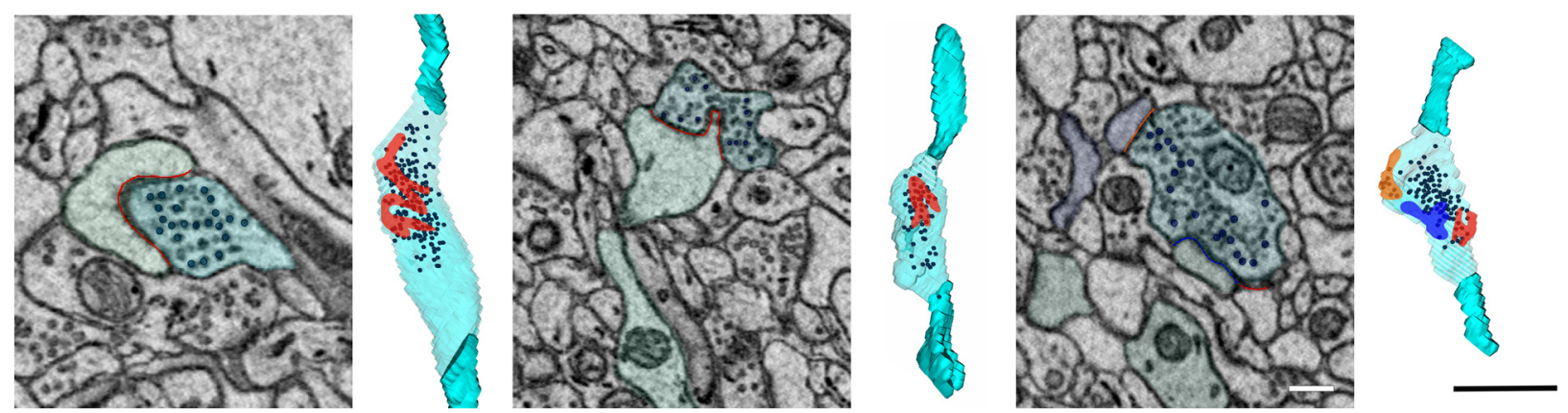

B
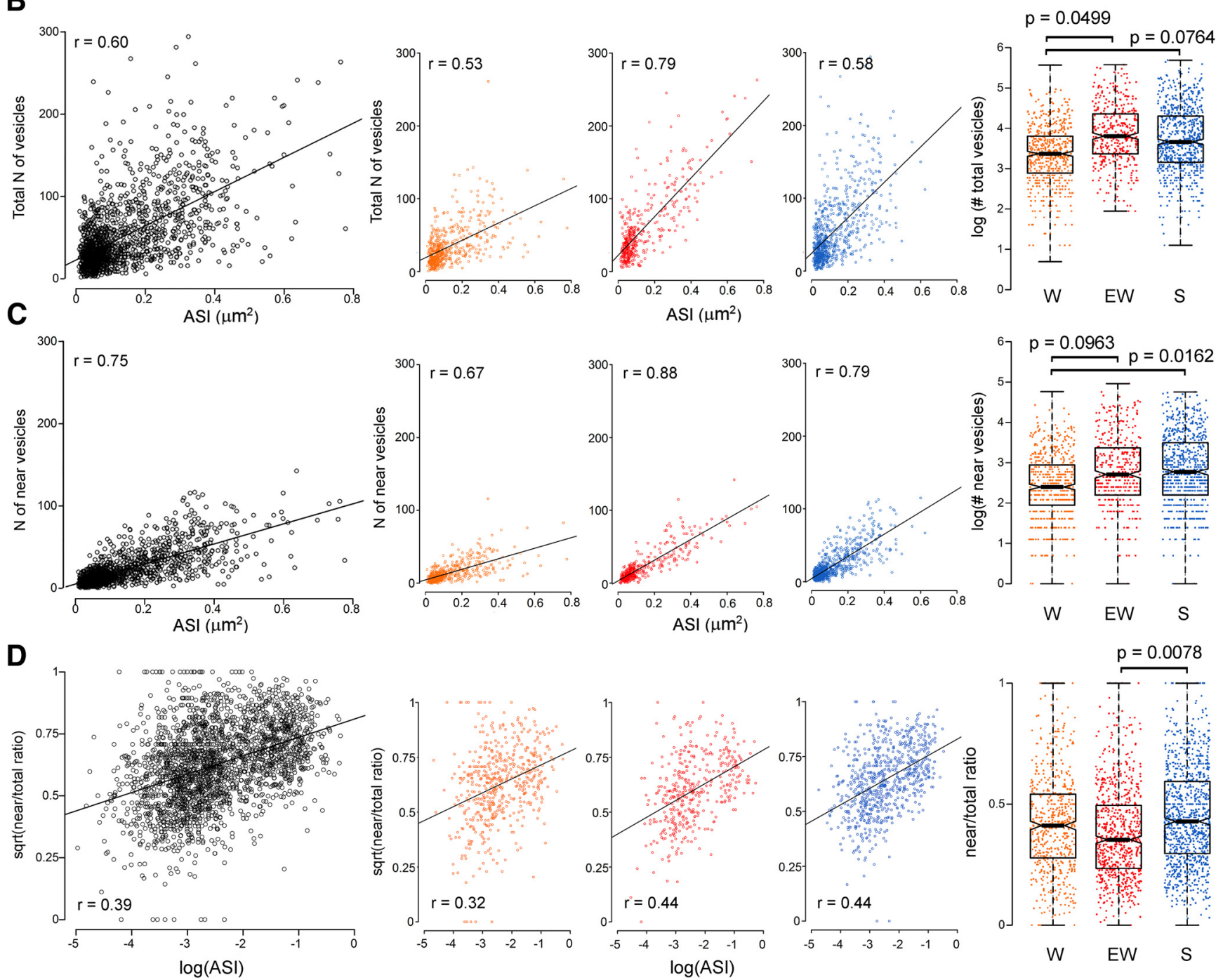

Figure 5. A, Examples of $3 \mathrm{D}$ reconstructions of 3 axonal boutons (light blue) with synaptic vesicles and ASI (red area), including a multisynaptic bouton (right; with 3 ASIs) that was not used for the analysis. Scale bars: 2D $300 \mathrm{~nm} ; 3 \mathrm{D}, 1 \mu \mathrm{m}$. In each 2D image the black circles indicate the vesicles that were counted in that section. $\boldsymbol{B}-\boldsymbol{D}$, Correlations between ASI size and synaptic vesicles (number of total and near vesicles, and near/total ratio) shown across all mice (left) and separately for each experimental group (middle). Right, Effect of condition on total vesicle number, number of near vesicles, and near/total ratio: for an ASI of average size, W boutons have fewer total and near vesicles, and EW boutons have smaller near/total ratio. Each dot represents one bouton.

counted (Fig. 5A). In line with previous work (Harris and Stevens, 1989; Schikorski and Stevens, 1997) we found that ASI size positively correlated with the total number of vesicles and with the number of near vesicles (all, $r=0.60$; near, $r=0.75$; Fig. $5 B, C$ left). When split by condition, these correlations were strongest for $\mathrm{EW}$, intermediate for $\mathrm{S}$ and weakest for W (Fig. $5 \mathrm{~B}, \mathrm{C}$ middle). We therefore fitted an LME model that included condition, $\log (\mathrm{ASI})$ and their interaction as fixed effects, and dendrite and mouse as random effects (see Materials and Methods; Table 4). This model revealed a trend interaction between condition and $\log (\mathrm{ASI})(p=0.060)$ and a significant overall effect of condition (vs a model with both the interaction and main effect removed; $p=0.0254)$. Post hoc analysis found that, for a synapse with ASI of average size, the total number of vesicles was significantly smaller in $\mathrm{W}$ relative to $\mathrm{EW}(\mathrm{W}<\mathrm{EW}, p=0.0499)$ and showed a trend decrease in $\mathrm{W}$ relative to $\mathrm{S}(\mathrm{W}<\mathrm{S}, p=0.0764)$, with no change 
between $S$ and EW ( $p=0.8457$; Fig. $5 B$, right). When the same LME model (condition, $\log$ (ASI) and their interaction as fixed effects, dendrite and mouse as random effects; Materials and Methods; Table 4) was applied to the near vesicles the results were very similar, and this time the interaction between condition and $\log$ (ASI) reached significance $(p=0.0003)$. Post hoc analysis showed that the number of near vesicles for a synapse with mean ASI was significantly smaller in $\mathrm{W}$ relative to $\mathrm{S}(\mathrm{W}<\mathrm{S}, p=$ $0.0162)$ and showed a trend decrease in $\mathrm{W}$ relative to $\mathrm{EW}(\mathrm{W}<$ $\mathrm{EW}, p=0.0963)$ with no difference between $\mathrm{S}$ and EW ( $p=$ 0.9583; Fig. 5C, right).

We also considered the ratio between the number of near vesicles and total number of vesicles. The square root of this ratio showed an approximately linear correlation with $\log$ (ASI) $(r=$ 0.39 ) with similar strength across groups (Fig. $5 D$, left, middle). Fitting an LME model (Materials and Methods; Table 4) with condition and $\log$ (ASI) as fixed effects, and dendrite intercept, mouse intercept, and mouse ASI slope as random effects, revealed a significant main effect of condition $(p=0.0314)$. Post hoc analysis found that for a synapse with mean ASI, EW boutons showed a significantly lower near/total ratio relative to $S$ boutons $(p=0.0078)$, while the decrease relative to $\mathrm{W}$ boutons was not significant $(p=0.1142)$. W and $\mathrm{S}$ boutons showed very similar near/total ratios ( $p=0.6101$; Fig. $5 D$ right).

In summary, for the same average ASI size $\mathrm{W}$ boutons had a smaller total number of synaptic vesicles than $S$ and EW boutons, and fewer vesicles closer to the cleft. Moreover, EW boutons had the lowest proportion of readily available vesicles.

\section{Discussion}

Overall, CA1 synapses had larger ASIs after wake than after sleep and nonperforated synapses grew in number after extended wake. Structural and functional measures of synaptic strength are linked (Holtmaat and Svoboda, 2009; Nishiyama and Yasuda, 2015), a relation that holds in CA1 stratum radiatum (Matsuzaki et al., 2001, 2004; Katz et al., 2009; Bosch et al., 2014). Thus, our results are consistent with the idea that in hippocampus, as in cortex, synaptic strength is higher after wake and lower after sleep. Our results also suggest, as discussed below, that synaptic changes in CA1 depend on the amount of learning and plasticity occurring during wake. We do not know whether similar sleep/ wake changes would occur in mice kept in isolated conditions and with no access to novel objects and/or a running wheel.

\section{Learning effects on hippocampal synapses}

In vitro experiments have shown that the increase in synaptic strength observed in the hippocampus 1-2 $\mathrm{h}$ after electricallyinduced long-term potentiation (LTP) is associated with a shift in the distribution of PSD sizes toward higher values, without changes in synaptic density or with a decrease in the number of the smallest, hence weakest, spines (Muller et al., 2000; Weeks et al., 2000; Toni et al., 2001; Bourne and Harris, 2011), many of which may have been silent (Ganeshina et al., 2004). In vivo, an increase in synapse size occurs several hours after LTP induction or learning, accompanied by no change or by an increase in synapse density, for example after spatial or avoidance learning (O'Malley et al., 1998, 2000). In the dentate gyrus of anesthetized rats synaptic density does not change $6 \mathrm{~h}$ after LTP induction, but the volume of nonperforated and perforated synapses increases (Popov et al., 2004). In freely moving rats, LTP induction in dentate gyrus also leads to an early increase in the number of spines with long synaptic appositions and strongly reactive for F-actin (Fukazawa et al., 2003), which is enriched in large syn- apses (Capani et al., 2001). Finally, spine density increases in the basal dendrites of CA1 neurons of adult rats after prolonged spatial training in an enriched environment (Moser et al., 1994), but not after spatial training without enrichment (Rusakov et al., 1997). Overall, then, the increases in synapse size and density we observed in the hippocampus after extended, enriched wake are consistent with those induced by learning paradigms in vivo.

\section{Sleep/wake effects in hippocampus and cortex}

The present results show that, overall, ASI size is higher after wake than after sleep not only in the cerebral cortex, but also in the CA1 region of the hippocampus. However, there are interesting differences between these two brain areas. In the cerebral cortex, spontaneous and extended wake led to similar increases in ASI relative to sleep (de Vivo et al., 2017), whereas hippocampal ASI sizes were highest after extended wake. Furthermore, cortical changes in ASI sizes followed a scaling relationship, whereas in hippocampus this was the case only for perforated synapses. Finally, synapse number did not change in cortex but did so in hippocampus after extended wake. These results probably reflect differences between the two regions, because experimental conditions were matched between the two studies. One difference may relate to the key role of the hippocampus as novelty detector, which likely enables CA1 neurons to produce more finely tuned and graded responses to different levels of novelty than neurons in primary cortex (Giovannini et al., 2001; VanElzakker et al., 2008). For instance, strong Fos induction occurs in somatosensory cortex independent of the extent of environmental novelty, while Fos expression in CA1 neurons increase progressively with the number of novel objects (VanElzakker et al., 2008). Another difference is suggested by long-term imaging experiments showing that most, if not all, CA1 synapses in the adult mouse are impermanent, with a mean lifespan of 1-2 weeks (Attardo et al., 2015). The same study estimated that $>50 \%$ of spines in primary cortex are instead permanent, whereas the rest have a lifetime of $\sim 5 \mathrm{~d}$ (Attardo et al., 2015). Thus, the broader changes in size and number seen after extended wake in CA1 synapses relative to cortical synapses may reflect the primary role of the hippocampus in novelty detection, as well as perhaps greater dynamics consistent with their impermanence (Attardo et al., 2015).

On the other hand, when spontaneous wake was compared with sleep, hippocampal synapses showed more limited changes than cortical synapses. Several factors may have contributed to these findings. One explanation may relate to differences in neural activity during spontaneous wake between these two regions. Both cortex and hippocampus show irregular, fast activity during active exploratory wake, strikingly different from the slow activity associated with NREM sleep. However, during non-exploratory wake, which makes up a sizable fraction of spontaneous wake, activity in cortex remains closer to that during exploratory wake than to sleep, while in the hippocampus it resembles NREM sleep. Specifically, sharp waves/ripples, large hippocampal field potentials that occur most frequently during NREM sleep, are also frequent during non-exploratory wake (Joo and Frank, 2018). W mice had access to a running wheel and to a few objects, but their exposure to novelty was less than in EW mice. Thus, sharp waves/ripples likely occurred more frequently in $\mathrm{W}$ mice, which were awake $86 \%$ of the last $6 \mathrm{~h}$ and were not prompted to explore, than in EW mice, which were kept awake $100 \%$ of the time by encouraging exploration. Given their recently proposed role in synaptic downscaling (Norimoto et al., 2018), it is possible that sharp waves/ripples resulted in synaptic renormalization during non-exploratory periods of spontaneous wake, especially 
for the smaller, nonperforated synapses. Another possibility, linked to their graded response to novelty, is that most CA1 neurons, unlike cortical neurons, reached the threshold to induce structural synaptic changes only after extended, enriched wake. We also cannot rule out that different levels of stress hormones contributed to the differences between $\mathrm{W}$ and $\mathrm{EW}$ mice in the hippocampus, but not in the cortex. Moreover, the expression of Per2 and Homerla in the whole mouse brain varies depending on the time of day when sleep deprivation was performed (Curie et al., 2013). Thus, we cannot rule out time of day effects on the expression of genes that can influence synaptic strength. If so, however, one will need to assume that these circadian effects occurred in the hippocampus but not in the cortex.

Another difference between the cerebral cortex and the CA1 region of the hippocampus concerns the distribution of synaptic sizes. In the cerebral cortex and several other brain regions, including CA3 and dentate gyrus, synaptic size and amplitude of evoked EPSP follow a log-normal distribution (Song et al., 2005; Sarid et al., 2007; Lefort et al., 2009; Loewenstein et al., 2011; Ikegaya et al., 2013; Bromer et al., 2018). In our CA1 samples, however, ASI sizes followed a bimodal distribution, with the largest synapses, most of which are perforated and contain many AMPA and NMDA receptors (Nusser et al., 1998; Takumi et al., 1999; Ganeshina et al., 2004; Nicholson et al., 2006; Nicholson and Geinisman, 2009), accounting for a greater proportion of all synapses than in a log-normal distribution. Even small changes in this sizable minority of strong synapses can be expected to have a profound impact on network dynamics, because they account for the largest fraction of total synaptic weight (Song et al., 2005; Teramae and Fukai, 2014). For instance, the weakest $50 \%$ of CA3 excitatory synapses contributes $17 \%$ of the overall synaptic conductance, whereas the strongest $20 \%$ accounts for $52 \%$ of it (Ikegaya et al., 2013). In cortex, at least at the population level, the largest $20 \%$ of synapses did not change in ASI size between sleep and wake, even after extended wake, possibly because they were already committed to strong memories and saturated. In CA1, we found that perforated synapses increased in size after spontaneous wake and even more so after extended wake, suggesting that these synapses may be especially plastic (Muller et al., 2000). Indeed, even the largest CA1 synapses were smaller than the largest cortical synapses, suggesting that they were still far from saturation.

\section{Increased synapse density after sleep deprivation}

In our protocol, extended wake led to higher density of CA1 synapses rather than to spine loss as reported by Havekes et al. (2016). We used novel objects to elicit active exploration, whereas Havekes et al. (2016) used gentle handling (cage shaking, lid removal, etc.) with the specific goal of limiting novelty exposure as much as possible. Thus, a key difference between the two studies is that synaptic plasticity was triggered more prominently with our method of sleep deprivation, while other factors such as stress are less likely to account for the opposite findings. Specifically, at least one pilot study in our laboratory found that novelty exposure and gentle handling lead to a similar increase in corticosterone levels (Bellesi et al., 2018b). The fact that we used mice of both sexes and Havekes et al. (2016) used only males also suggest that stress was not a key factor, because one study in rats found that acute stress increases the density of CA1 spines in males but decreases it in females (Shors et al., 2001). In the study by Havekes et al. (2016) total spine density measured using Golgi staining varied between control and sleep deprived mice, as well as between two groups of non-sleep deprived (control) animals collected $<3 \mathrm{~h}$ apart. Further experiments will be important to clarify whether this variability reflects true differences because of circadian time, or technical variability. Experiments that combine Golgi staining and SBEM, and use different methods to enforce wake, will also be helpful.

\section{Sleep/wake effects on presynaptic markers}

Presynaptic and postsynaptic morphological measures of synaptic strength are correlated (Harris and Stevens, 1989; Schikorski and Stevens, 1997; Meyer et al., 2014; Bartol et al., 2015), a finding confirmed in our samples where vesicle number was correlated with ASI size. This correlation was weaker in W boutons, which had fewer vesicles than $S$ and EW boutons for synapses of mean ASI size. This result applied to both total and near vesicles, suggesting a general imbalance between number of vesicles and ASI. A transient imbalance in presynaptic and postsynaptic morphological markers was observed in CA1 hippocampal slices after glutamate uncaging (Meyer et al., 2014), which caused an early spine enlargement followed, $3 \mathrm{~h}$ later, by the growth of the axonal bouton (Meyer et al., 2014). Thus, it is possible that after spontaneous wake there was a temporal dissociation between the rapid growth of some spines and that of their boutons, an imbalance that disappeared after extended wake.

Presynaptic fatigue is rarely discussed in the context of synaptic plasticity but, following LTP induction, neocortical pyramidal neurons were found to respond to high-frequency trains of presynaptic action potentials with a redistribution of synaptic efficacy: relative to baseline, the initial EPSP was larger, but the subsequent ones decreased at a faster rate (Markram and Tsodyks, 1996), consistent with enhanced failure in glutamate release (O'Donovan and Rinzel, 1997). We found that, for a synapse with average ASI size, hippocampal EW boutons showed the smallest near/total ratio, indicating a smaller proportion of readily available vesicles. This finding, if confirmed in a larger sample of boutons and extended to other brain areas, could indicate that forcing wake beyond its physiological duration may lead to presynaptic fatigue.

\section{References}

Attardo A, Fitzgerald JE, Schnitzer MJ (2015) Impermanence of dendritic spines in live adult CA1 hippocampus. Nature 523:592-596.

Barr DJ (2013) Random effects structure for testing interactions in linear mixed-effects models. Front Psychol 4:328.

Bartol TM, Bromer C, Kinney J, Chirillo MA, Bourne JN, Harris KM, Sejnowski TJ (2015) Nanoconnectomic upper bound on the variability of synaptic plasticity. Elife 4:e10778.

Bates D, Maechler M, Bolker B, Walker S (2015) Fitting linear mixed-effects models using lme4. J Stat Softw 67:1-48.

Bellesi M, Pfister-Genskow M, Maret S, Keles S, Tononi G, Cirelli C (2013) Effects of sleep and wake on oligodendrocytes and their precursors. J Neurosci 33:14288-14300.

Bellesi M, de Vivo L, Tononi G, Cirelli C (2015) Effects of sleep and wake on astrocytes: clues from molecular and ultrastructural studies. BMC Biol 13:66.

Bellesi M, de Vivo L, Koebe S, Tononi G, Cirelli C (2018a) Sleep and wake affect glycogen content and turnover at perisynaptic astrocytic processes. Front Cell Neurosci 12:308.

Bellesi M, Haswell JD, de Vivo L, Marshall W, Roseboom PH, Tononi G, Cirelli C (2018b) Myelin modifications after chronic sleep loss in adolescent mice. Sleep 41:zsy034.

Berry KP, Nedivi E (2017) Spine dynamics: are they all the same? Neuron 96:43-55.

Bosch M, Castro J, Saneyoshi T, Matsuno H, Sur M, Hayashi Y (2014) Structural and molecular remodeling of dendritic spine substructures during long-term potentiation. Neuron 82:444-459.

Bourne JN, Harris KM (2011) Coordination of size and number of excitatory and inhibitory synapses results in a balanced structural plasticity 
along mature hippocampal CA1 dendrites during LTP. Hippocampus 21:354-373.

Bretz F, Hothorn T, Westfall P (2011) Multiple comparisons using R. Boca Raton, FL: CRC.

Bromer C, Bartol TM, Bowden JB, Hubbard DD, Hanka DC, Gonzalez PV, Kuwajima M, Mendenhall JM, Parker PH, Abraham WC, Sejnowski TJ, Harris KM (2018) Long-term potentiation expands information content of hippocampal dentate gyrus synapses. Proc Natl Acad Sci U S A 115:E2410-E2418.

Buchs PA, Muller D (1996) Induction of long-term potentiation is associated with major ultrastructural changes of activated synapses. Proc Natl Acad Sci U S A 93:8040-8045.

Capani F, Martone ME, Deerinck TJ, Ellisman MH (2001) Selective localization of high concentrations of F-actin in subpopulations of dendritic spines in rat central nervous system: a three-dimensional electron microscopic study. J Comp Neurol 435:156-170.

Cardona A, Saalfeld S, Schindelin J, Arganda-Carreras I, Preibisch S, Longair M, Tomancak P, Hartenstein V, Douglas RJ (2012) TrakEM2 software for neural circuit reconstruction. PLoS One 7:e38011.

Cheetham CE, Barnes SJ, Albieri G, Knott GW, Finnerty GT (2014) Pansynaptic enlargement at adult cortical connections strengthened by experience. Cereb Cortex 24:521-531.

Cirelli C (2017) Sleep, synaptic homeostasis and neuronal firing rates. Curr Opin Neurobiol 44:72-79.

Cooney JR, Hurlburt JL, Selig DK, Harris KM, Fiala JC (2002) Endosomal compartments serve multiple hippocampal dendritic spines from a widespread rather than a local store of recycling membrane. J Neurosci 22: 2215-2224.

Curie T, Mongrain V, Dorsaz S, Mang GM, Emmenegger Y, Franken P (2013) Homeostatic and circadian contribution to EEG and molecular state variables of sleep regulation. Sleep 36:311-323.

Debanne D, Gähwiler BH, Thompson SM (1996) Cooperative interactions in the induction of long-term potentiation and depression of synaptic excitation between hippocampal CA3-CA1 cell pairs in vitro. Proc Natl Acad Sci U S A 93:11225-11230.

Desmond NL, Levy WB (1988) Synaptic interface surface area increases with long-term potentiation in the hippocampal dentate gyrus. Brain Res 453:308-314.

de Vivo L, Bellesi M, Marshall W, Bushong EA, Ellisman MH, Tononi G, Cirelli C (2017) Ultrastructural evidence for synaptic scaling across the wake/sleep cycle. Science 355:507-510.

Diering GH, Nirujogi RS, Roth RH, Worley PF, Pandey A, Huganir RL (2017) Homerla drives homeostatic scaling-down of excitatory synapses during sleep. Science 355:511-515.

Feng G, Mellor RH, Bernstein M, Keller-Peck C, Nguyen QT, Wallace M, Nerbonne JM, Lichtman JW, Sanes JR (2000) Imaging neuronal subsets in transgenic mice expressing multiple spectral variants of GFP. Neuron 28:41-51.

Fiala JC, Harris KM (2001) Cylindrical diameters method for calibrating section thickness in serial electron microscopy. J Microsc 202:468-472.

Fukazawa Y, Saitoh Y, Ozawa F, Ohta Y, Mizuno K, Inokuchi K (2003) Hippocampal LTP is accompanied by enhanced F-actin content within the dendritic spine that is essential for late LTP maintenance in vivo. Neuron 38:447-460.

Ganeshina O, Berry RW, Petralia RS, Nicholson DA, Geinisman Y (2004) Differences in the expression of AMPA and NMDA receptors between axospinous perforated and nonperforated synapses are related to the configuration and size of postsynaptic densities. J Comp Neurol 468:86-95.

Giovannini MG, Rakovska A, Benton RS, Pazzagli M, Bianchi L, Pepeu G (2001) Effects of novelty and habituation on acetylcholine, GABA, and glutamate release from the frontal cortex and hippocampus of freely moving rats. Neuroscience 106:43-53.

Harris KM, Stevens JK (1989) Dendritic spines of CA 1 pyramidal cells in the rat hippocampus: serial electron microscopy with reference to their biophysical characteristics. J Neurosci 9:2982-2997.

Harris KM, Weinberg RJ (2012) Ultrastructure of synapses in the mammalian brain. Cold Spring Harb Perspect Biol 4:a005587.

Havekes R, Park AJ, Tudor JC, Luczak VG, Hansen RT, Ferri SL, Bruinenberg VM, Poplawski SG, Day JP, Aton SJ, Radwańska K, Meerlo P, Houslay MD, Baillie GS, Abel T (2016) Sleep deprivation causes memory deficits by negatively impacting neuronal connectivity in hippocampal area CA1. eLife 5:e13424.
Holtmaat A, Svoboda K (2009) Experience-dependent structural synaptic plasticity in the mammalian brain. Nat Rev Neurosci 10:647-658.

Ikegaya Y, Sasaki T, Ishikawa D, Honma N, Tao K, Takahashi N, Minamisawa G, Ujita S, Matsuki N (2013) Interpyramid spike transmission stabilizes the sparseness of recurrent network activity. Cereb Cortex 23:293-304.

Joo HR, Frank LM (2018) The hippocampal sharp wave-ripple in memory retrieval for immediate use and consolidation. Nat Rev Neurosci 19:744-757.

Kasthuri N, Hayworth KJ, Berger DR, Schalek RL, Conchello JA, KnowlesBarley S, Lee D, Vázquez-Reina A, Kaynig V, Jones TR, Roberts M, Morgan JL, Tapia JC, Seung HS, Roncal WG, Vogelstein JT, Burns R, Sussman DL, Priebe CE, Pfister H, Lichtman JW (2015) Saturated reconstruction of a volume of neocortex. Cell 162:648-661.

Katz Y, Menon V, Nicholson DA, Geinisman Y, Kath WL, Spruston N (2009) Synapse distribution suggests a two-stage model of dendritic integration in CA1 pyramidal neurons. Neuron 63:171-177.

Knott GW, Holtmaat A, Wilbrecht L, Welker E, Svoboda K (2006) Spine growth precedes synapse formation in the adult neocortex in vivo. Nat Neurosci 9:1117-1124.

Laird NM, Ware JH (1982) Random effects models for longitudinal data. Biometrics 38:963-974.

Lefort S, Tomm C, Floyd Sarria JC, Petersen CC (2009) The excitatory neuronal network of the $\mathrm{C} 2$ barrel column in mouse primary somatosensory cortex. Neuron 61:301-316.

Loewenstein Y, Kuras A, Rumpel S (2011) Multiplicative dynamics underlie the emergence of the log-normal distribution of spine sizes in the neocortex in vivo. J Neurosci 31:9481-9488.

Lubenov EV, Siapas AG (2008) Decoupling through synchrony in neuronal circuits with propagation delays. Neuron 58:118-131.

Maret S, Faraguna U, Nelson AB, Cirelli C, Tononi G (2011) Sleep and waking modulate spine turnover in the adolescent mouse cortex. Nat Neurosci 14:1418-1420.

Markram H, Tsodyks M (1996) Redistribution of synaptic efficacy between neocortical pyramidal neurons. Nature 382:807-810.

Matsuzaki M, Ellis-Davies GC, Nemoto T, Miyashita Y, Iino M, Kasai H (2001) Dendritic spine geometry is critical for AMPA receptor expression in hippocampal CAl pyramidal neurons. Nat Neurosci 4:10861092.

Matsuzaki M, Honkura N, Ellis-Davies GC, Kasai H (2004) Structural basis of long-term potentiation in single dendritic spines. Nature 429:761-766.

Menon V, Musial TF, Liu A, Katz Y, Kath WL, Spruston N, Nicholson DA (2013) Balanced synaptic impact via distance-dependent synapse distribution and complementary expression of AMPARs and NMDARs in hippocampal dendrites. Neuron 80:1451-1463.

Meyer D, Bonhoeffer T, Scheuss V (2014) Balance and stability of synaptic structures during synaptic plasticity. Neuron 82:430-443.

Moser MB, Trommald M, Andersen P (1994) An increase in dendritic spine density on hippocampal CA1 pyramidal cells following spatial learning in adult rats suggests the formation of new synapses. Proc Natl Acad Sci U S A 91:12673-12675.

Muller D, Toni N, Buchs PA (2000) Spine changes associated with longterm potentiation. Hippocampus 10:596-604.

Nelson AB, Faraguna U, Zoltan JT, Tononi G, Cirelli C (2013) Sleep patterns and homeostatic mechanisms in adolescent mice. Brain Sci 3:318343.

Nicholson DA, Geinisman Y (2009) Axospinous synaptic subtype-specific differences in structure, size, ionotropic receptor expression, and connectivity in apical dendritic regions of rat hippocampal CA1 pyramidal neurons. J Comp Neurol 512:399-418.

Nicholson DA, Trana R, Katz Y, Kath WL, Spruston N, Geinisman Y (2006) Distance-dependent differences in synapse number and AMPA receptor expression in hippocampal CA1 pyramidal neurons. Neuron 50:431-442.

Nicoll RA, Schmitz D (2005) Synaptic plasticity at hippocampal mossy fibre synapses. Nat Rev Neurosci 6:863-876.

Nishiyama J, Yasuda R (2015) Biochemical computation for spine structural plasticity. Neuron 87:63-75.

Norimoto H, Makino K, Gao M, Shikano Y, Okamoto K, Ishikawa T, Sasaki T, Hioki H, Fujisawa S, Ikegaya Y (2018) Hippocampal ripples downregulate synapses. Science 359:1524-1527.

Nusser Z, Lujan R, Laube G, Roberts JD, Molnar E, Somogyi P (1998) Cell type and pathway dependence of synaptic AMPA receptor number and variability in the hippocampus. Neuron 21:545-559. 
O’Donovan MJ, Rinzel J (1997) Synaptic depression: a dynamic regulator of synaptic communication with varied functional roles. Trends Neurosci $20: 431-433$

O’Malley A, O’Connell C, Regan CM (1998) Ultrastructural analysis reveals avoidance conditioning to induce a transient increase in hippocampal dentate spine density in the 6 hour training period of consolidation. Neuroscience 87:607-613.

O’Malley A, O’Connell C, Murphy KJ, Regan CM (2000) Transient spine density increases in the mid-molecular layer of hippocampal dentate gyrus accompany consolidation of a spatial learning task in the rodent. Neuroscience 99:229-232.

Popov VI, Davies HA, Rogachevsky VV, Patrushev IV, Errington ML, Gabbott PL, Bliss TV, Stewart MG (2004) Remodelling of synaptic morphology but unchanged synaptic density during late phase long-term potentiation (LTP): a serial section electron micrograph study in the dentate gyrus in the anaesthetised rat. Neuroscience 128:251-262.

Raven F, Meerlo P, Van der Zee EA, Abel T, Havekes R (2019) A brief period of sleep deprivation causes spine loss in the dentate gyrus of mice. Neurobiol Learn Mem 160:83-90.

Routh BN, Johnston D, Harris K, Chitwood RA (2009) Anatomical and electrophysiological comparison of CA1 pyramidal neurons of the rat and mouse. J Neurophysiol 102:2288-2302.

Rusakov DA, Davies HA, Harrison E, Diana G, Richter-Levin G, Bliss TV, Stewart MG (1997) Ultrastructural synaptic correlates of spatial learning in rat hippocampus. Neuroscience 80:69-77.

Sarid L, Bruno R, Sakmann B, Segev I, Feldmeyer D (2007) Modeling a layer 4-to-layer 2/3 module of a single column in rat neocortex: interweaving in vitro and in vivo experimental observations. Proc Natl Acad Sci U S A 104:16353-16358.

Schikorski T, Stevens CF (1997) Quantitative ultrastructural analysis of hippocampal excitatory synapses. J Neurosci 17:5858-5867.

Schindelin J, Arganda-Carreras I, Frise E, Kaynig V, Longair M, Pietzsch T, Preibisch S, Rueden C, Saalfeld S, Schmid B, Tinevez JY, White DJ, Hartenstein V, Eliceiri K, Tomancak P, Cardona A (2012) Fiji: an opensource platform for biological-image analysis. Nat Methods 9:676-682.

Shors TJ, Chua C, Falduto J (2001) Sex differences and opposite effects of stress on dendritic spine density in the male versus female hippocampus. J Neurosci 21:6292-6297.

Song S, Sjöström PJ, Reigl M, Nelson S, Chklovskii DB (2005) Highly nonrandom features of synaptic connectivity in local cortical circuits. PLoS Biol 3:e68.

Sorra KE, Harris KM (1993) Occurrence and three-dimensional structure of multiple synapses between individual radiatum axons and their target pyramidal cells in hippocampal area CA1. J Neurosci 13:3736-3748.

Sorra KE, Fiala JC, Harris KM (1998) Critical assessment of the involvement of perforations, spinules, and spine branching in hippocampal synapse formation. J Comp Neurol 398:225-240.

Takumi Y, Ramírez-León V, Laake P, Rinvik E, Ottersen OP (1999) Different modes of expression of AMPA and NMDA receptors in hippocampal synapses. Nat Neurosci 2:618-624.

Teramae JN, Fukai T (2014) Computational implications of lognormally distributed synaptic weights. Proc IEEE 102:500-512.

Toni N, Buchs PA, Nikonenko I, Povilaitite P, Parisi L, Muller D (2001) Remodeling of synaptic membranes after induction of long-term potentiation. J Neurosci 21:6245-6251.

Tononi G, Cirelli C (2014) Sleep and the price of plasticity: from synaptic and cellular homeostasis to memory consolidation and integration. Neuron 81:12-34.

VanElzakker M, Fevurly RD, Breindel T, Spencer RL (2008) Environmental novelty is associated with a selective increase in fos expression in the output elements of the hippocampal formation and the perirhinal cortex. Learn Mem 15:899-908.

Vyazovskiy VV, Cirelli C, Pfister-Genskow M, Faraguna U, Tononi G (2008) Molecular and electrophysiological evidence for net synaptic potentiation in wake and depression in sleep. Nat Neurosci 11:200-208.

Weeks AC, Ivanco TL, Leboutillier JC, Racine RJ, Petit TL (2000) Sequential changes in the synaptic structural profile following long-term potentiation in the rat dentate gyrus: II. Induction/early maintenance phase. Synapse 36:286-296.

Wilke SA, Antonios JK, Bushong EA, Badkoobehi A, Malek E, Hwang M, Terada M, Ellisman MH, Ghosh A (2013) Deconstructing complexity: serial block-face electron microscopic analysis of the hippocampal mossy fiber synapse. J Neurosci 33:507-522. 